\title{
Evaluation of Coupling and Coordinated Development of Marine Economic Policy and Marine Service Industry
}

\author{
Lv Zuoliang ${ }^{1, a}$, Li Bin $^{1, b}$ \\ ${ }^{1}$ School of Economics and Management, Dalian University, Dalian, China
}

\begin{abstract}
This article studies the coordinated development of marine economic policy and marine service industry by constructing a system for evaluating marine economic policy and marine service industry indicators and applying a coupled coordination degree model, and analyzes its development laws. The research shows that the coordinated development level of marine economic policy and marine service industry is on the rise, the interaction level among the elements in the system is enhanced, the cyclic cumulative causal effect and cluster advantage are enhanced, and the coordinated development level is adjusted from primary imbalance to primary coordination. Under the comprehensive effect of the stable curve law of the development of marine economic policies and the stable rising law of the development of marine service industry, the development of marine service industry is in good condition, and the development of marine economic policies lags behind. To further promote the high-quality development of marine service industry, the government can strengthen Guide the connection between the main factors of the two systems and the positive and dynamic response to further promote the coordinated development of the two.
\end{abstract}

\section{Coupling development mechanism of marine economic policy and marine service industry}

In recent years, the proportion of China's marine service industry in the three major marine industries has increased steadily, the marine industrial structure has been continuously optimized, and the marine economy has developed rapidly and stably.

From the external environment, the marine economic policy actively adapts to the continuous adjustment and optimization of the marine industry structure brought about by the development of the marine service industry, and plays an active role in guiding the development of the marine service industry. In addition, research related data found that my country's marine economic policy implementation is continuous, so it is meaningful to study the evolution of marine economic policy for the development of marine service industry.

According to China's "National Economic Industry Classification" standard and the relevant provisions of the marine industry division standard, marine service industry mainly includes marine transportation, coastal tourism, marine science and technology education management service industry and marine environmental protection industry, referring to the collection of the economic sectors in the marine sector and various sea-related enterprises that produce or provide various services. The stable and healthy development of the marine service industry has a practical test of the scientific, practicability and advanced nature of the marine economic policy, which enables the marine economic policy to continuously improve and keep pace with the times.

In summary, there is a coupling and coordination mechanism between the marine economic policy system and the marine service industry system. The coupling between the two systems is reflected in the coupling laws and movements of the structure, function, and connection between the marine economic policy subsystem and the marine service industry subsystem. The changes are embodied in three aspects: coupling power, coupling mechanism and coupling mode. The following is a combination of the actual development of my country's marine service industry and the evolution of marine economic policy to support and study empirical data, and explore the coupling mechanism between the two.

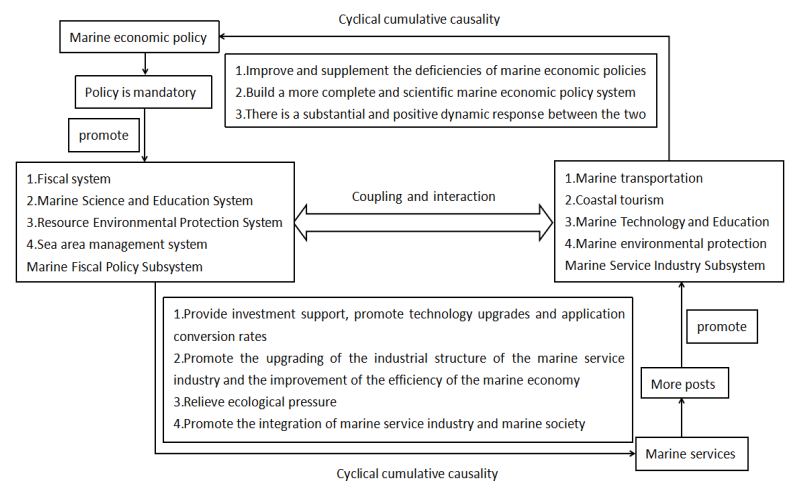

Fig1. Cooperative and coordinated mechanism diagram of marine economic policy and marine service industry 


\section{Research methods}

\subsection{Index system of coupling evaluation of marine economic policy and marine service industry}

Based on the analysis of the coupling and coordination mechanism between the marine economic policy and the marine service industry, the evaluation index system for the coupling of the marine economic policy and the marine service industry is shown in Table 1 . The construction of the index system follows the following principles: First, systematic and main components are taken into consideration; second, characteristics and regularity are taken into account; third, data availability and comparability are taken into account. Based on the above principles, and then refer to the relevant coupling mechanism index system to build literature, the index system is divided into three levels: system level, element level and index level. The element layer of the marine economic policy subsystem is divided into four element layers: marine science and education, resource environmental protection, sea area management, and transportation. The element layer of the ocean service industry subsystem is divided into marine transportation and coastal areas. There are four levels in tourism, marine science and technology and education, and marine environmental protection.

Table1. Evaluation Index System for Coupling and Coordination of Marine Economic Policy and Marine Service Industry

\begin{tabular}{|c|c|}
\hline System layer & Feature layer \\
\hline \multirow{4}{*}{$\begin{array}{l}\text { Marine Economic } \\
\text { Policy Evaluation } \\
\text { Subsystem }\end{array}$} & Marine Science and Education $(\mathrm{x} 1-\mathrm{x} 3)$ \\
\hline & $\begin{array}{l}\text { Resource and environmental protection } \\
(\mathrm{x} 4-\mathrm{x} 6)\end{array}$ \\
\hline & Sea area management $(x 7-x 9)$ \\
\hline & Transportation $\mathrm{x} 10$ \\
\hline \multirow{4}{*}{$\begin{array}{l}\text { Marine Service } \\
\text { Industry Rating } \\
\text { Subsystem }\end{array}$} & Marine transportation $(\mathrm{y} 1-\mathrm{y} 3)$ \\
\hline & Coastal tourism (y4-y6) \\
\hline & $\begin{array}{l}\text { Marine Technology and Education (y7- } \\
\text { y8) }\end{array}$ \\
\hline & $\begin{array}{l}\text { Marine environmental protection (y9- } \\
\text { y10) }\end{array}$ \\
\hline
\end{tabular}

\subsection{Research methods}

Coupling coordination degree model: Coupling refers to the phenomenon that two or more systems or forms of motion affect each other through various interactions, which reflects the intersection of coordinated development between various subsystems. There is a coupling effect between the subsystems of the marine economic policy and the subsystems of the marine service industry. This relationship is dynamic, interlaced, and unbalanced. Studying the benign and coordinated development of the two also catalyzes the positive development of the two themselves. According to the coupling definition, let the positive numbers $\mathrm{x} 1, \mathrm{x} 2$...xm be the " $\mathrm{m}$ " indicators of the marine economic policy system; let the $y 1, y 2 \ldots y n$ positive numbers be the " $n$ " indicators of the marine service industry system, then call the functions $\mathrm{F}(\mathrm{x}), \mathrm{F}(\mathrm{y})$ For the comprehensive marine economic policy evaluation function and the comprehensive marine service industry evaluation function:

$$
F(x)=\sum_{i=1}^{m} a_{i} x_{i} ; F(y)=\sum_{j=1}^{n} b_{i} y_{j}{ }^{\prime}
$$

In the formula, ai and bj are the undetermined weights of each indicator. In this paper, the quantitative scoring method can be used to obtain. In order to further evaluate the degree of mutual coupling between the marine economic policy and the marine service industry, a coupling coordination degree model is introduced:

$$
T=g F(x)+h F(y)
$$

In the formula, $\mathrm{T}$ is the comprehensive development index of marine economic policy and marine service industry, which reflects the comprehensive level of the two. Since the marine economic policy system and marine service industry system are equally important, $\mathrm{g}=\mathrm{h}=0.5$ is adopted in this paper.

$$
C=\left(\frac{F(x) \times F(y)}{F(x)+F(y)}\right)^{k}
$$

Where $\mathrm{C}$ is the coordination index of the marine economic policy system and the marine service industry system; $\mathrm{k}$ is the coordination coefficient, which is taken in this paper;

$$
D=(x, y)=\longdiv { C \times T }
$$

Coupling coordination index $\mathrm{D} \in[0,1]$, when $\mathrm{D}=1$, the coupling coordination degree is the largest, and good resonance coupling is achieved between the systems or the internal elements of the system, and the system will tend to a new ordered structure; when $\mathrm{D}=0$, The degree of coupling coordination is extremely small, and the systems or the internal elements of the system are in an irrelevant state, and the system will develop disorderly.

\subsection{Evaluation criteria and types}

The marine economic policies at the national level mainly appear in the form of laws, administrative regulations, departmental regulations and regulatory documents. According to the level of legal effectiveness, it is divided into four levels. The laws promulgated by the National People's Congress and the Standing Committee of the National People's Congress have the highest effectiveness. The policy intensity level is A, and the policy intensity score is 4 points; the regulations, directives and regulations issued by the State Council; The orders of various ministries and commissions are second only to the law and set at $\mathrm{B}$, with a score of 3 points; the provisional regulations and rules, plans, decisions, opinions, methods and standards promulgated by the State Council; the regulations, rules and decisions promulgated by various ministries and commissions are set as $\mathrm{C}$, etc., score 2 points; the definition of the effectiveness level of other normative documents is open to question. Here, the effectiveness is also classified as $\mathrm{D}$, and the score is 1 point.

The relevant papers could be referred on the classification standard of coupling and coordination type 
of urbanization and marine service industry development. On the basis of this research, this paper divides the coupling and coordinated development stage of marine economic policy and marine service industry into three major stages, namely the antagonistic stage, the break-in stage and Coordination stage. According to the relationship between the marine economic policy development index and the marine service industry development index, it is divided into the lagging type of marine economic policy development, the synchronous type of marine economic policy marine service industry development, and the lagging type of marine service industry. The specific evaluation criteria are shown in Table 2.

Table2. Evaluation Criteria of Coupling Coordination Degree of Marine Economic Policy and Marine Service Industry

\begin{tabular}{|c|c|c|}
\hline $\begin{array}{c}\text { Coordination } \\
\text { phase }\end{array}$ & $\begin{array}{l}\text { Coordination degree } \\
\text { and coordination level }\end{array}$ & $\begin{array}{c}\text { Type of } \\
\text { coordination }\end{array}$ \\
\hline \multirow{4}{*}{$\begin{array}{l}\text { Antagonistic } \\
\text { phase } \\
0 \leq \mathrm{D} \leq 0.45\end{array}$} & 0-0.09 Extreme disorder & \multirow{4}{*}{$\begin{array}{l}\text { Lagging type of } \\
\text { marine service } \\
\text { industry } \\
\mathrm{F}(\mathrm{x})>\mathrm{F}(\mathrm{y})\end{array}$} \\
\hline & $\begin{array}{l}0.10-0.19 \text { Severe } \\
\text { disorder }\end{array}$ & \\
\hline & $\begin{array}{l}0.20-0.29 \text { Moderate } \\
\text { disorder }\end{array}$ & \\
\hline & $0.30-0.45$ Mild disorder & \\
\hline \multirow{3}{*}{$\begin{array}{l}\text { Run-in phase } \\
0.45<\mathrm{D}<0.69\end{array}$} & $\begin{array}{l}0.46-0.49 \text { Imminent } \\
\text { imbalance }\end{array}$ & \multirow{3}{*}{$\begin{array}{l}\text { Lagging of the } \\
\text { development of } \\
\text { marine economic } \\
\text { policy } \\
\mathrm{F}(\mathrm{x})<\mathrm{F}(\mathrm{y})\end{array}$} \\
\hline & $\begin{array}{l}0.50-0.59 \text { Barely } \\
\text { coordinated }\end{array}$ & \\
\hline & $\begin{array}{l}0.60-0.69 \text { Primary } \\
\text { coordination }\end{array}$ & \\
\hline \multirow{3}{*}{$\begin{array}{l}\text { Coordination } \\
\text { phase } \\
0.7 \leq \mathrm{D} \leq 1\end{array}$} & $\begin{array}{l}0.70-0.79 \text { Intermediate } \\
\text { coordination }\end{array}$ & \multirow{3}{*}{$\begin{array}{l}\text { Synchronization of } \\
\text { marine economic } \\
\text { policy and marine } \\
\text { service industry } \\
\mathrm{F}(\mathrm{x})=\mathrm{F}(\mathrm{y})\end{array}$} \\
\hline & $\begin{array}{l}0.80-0.89 \text { Well } \\
\text { coordinated }\end{array}$ & \\
\hline & $\begin{array}{l}0.90-1.00 \text { Quality } \\
\text { coordination }\end{array}$ & \\
\hline
\end{tabular}

\section{Analysis of the spatiotemporal evolution of coupled systems}

\subsection{Data sources}

Based on the above classification and related materials, this article has carried out statistics and analysis on 247 marine economic policies (taking into account the historical and social reasons of New China, focusing on the marine economic policies from 1978 to 2017), as shown in Table 3 below.

Table3. Statistics table of China's marine economic policies and regulations from 1978 to 2017

\begin{tabular}{|l|l|l|l|l|l|}
\hline \multirow{2}{*}{ Marine economic policy categories } & \multicolumn{5}{|c|}{ grade } \\
\cline { 2 - 7 } & $\boldsymbol{A}$ & $\boldsymbol{B}$ & $\boldsymbol{C}$ & \multicolumn{1}{|c|}{$\boldsymbol{D}$} & total \\
\hline Marine Fisheries Policy & 2 & 2 & 15 & 16 & 35 \\
\hline Marine mining policy & 1 & & 1 & 4 & 6 \\
\hline Marine transportation policy & 3 & 12 & 38 & 23 & 76 \\
\hline Offshore Oil and Gas Industry Policy & & 4 & 6 & 5 & 15 \\
\hline Marine Ship Industry Policy & & & 3 & 6 & 9 \\
\hline Marine Engineering and Construction Policy & & 3 & 8 & 2 & 13 \\
\hline Marine Power Industry Policy & & & & 5 & 5 \\
\hline Seawater utilization policy & & & & 6 & 6 \\
\hline Marine Science and Technology Policy & & 1 & & 12 & 13 \\
\hline $\begin{array}{l}\text { Marine Resources Environmental Protection } \\
\text { Policy }\end{array}$ & 3 & 10 & 11 & 13 & 37 \\
\hline Sea area management policy & 2 & & 3 & 16 & 21 \\
\hline Comprehensive Marine Economic Policy & 2 & & & 9 & 11 \\
\hline total & 13 & 32 & 85 & 117 & 247 \\
\hline
\end{tabular}

Based on the comprehensive analysis of the statistical results in Table 3 and Table 1, marine economic policies mainly affect marine science and education, marine environmental protection, marine transportation, and marine area management in the marine service industry. Among them, the total number of marine transportation policies is the largest, and the four-level policies of A, B, $\mathrm{C}$, and $\mathrm{D}$ are the most powerful. Therefore, in general, the weight of such policies is the highest, giving $3 \mathrm{~A}+12 \mathrm{~B}+38 \mathrm{C}+23 \mathrm{D}=147$ points; For marine resources environmental protection policies, 3 policies such as A, 10 policies such as $\mathrm{B}$, etc., the policy is more effective, giving $3 \mathrm{~A}+10 \mathrm{~B}+11 \mathrm{C}+13 \mathrm{D}=77$ points; marine management policies, 2 policies such as $\mathrm{A}, \mathrm{C}$, etc. $\mathrm{D}$ and other policies are more than marine science and technology policies, giving $2 \mathrm{~A}+3 \mathrm{C}+16 \mathrm{D}=30$ points; finally, marine science and technology policies give $\mathrm{B}+12 \mathrm{D}=15$ points, reducing the score of various policies by 1,000 times, which is the index of various types. Attach weights.

\subsection{Evaluation results and analysis}

Through the quantitative scoring method, each index in the evaluation index system is given weight. Taking the national marine service industry and marine economic policy data as the research object, and taking the numerical values of various indicators of the marine economic policy and marine service industry system in the research period (2006-2015) as the sample data, the evaluation indicators involved in this article are all Positive data, so in this paper, the extreme value method is used to dimensionlessly process the collected data, the formula:

$$
x_{i}{ }^{\prime}=\frac{x_{i}}{\operatorname{Max}_{x_{i}}}
$$

Using the coupled coordination model method, the index table for the coordinated development of China's marine economic policy and marine service industry system and the evaluation table for the coordinated development types of my country's marine economic policy and marine service industry system are obtained, as shown in Tables 4 and 5, respectively.

Table4. Index of Coordinated Development of Marine Economic Policy and Marine Service Industry

\begin{tabular}{|l|l|l|l|l|}
\hline $\begin{array}{c}\text { progressio } \\
\text { n stage }\end{array}$ & years & $\begin{array}{c}\text { Marine } \\
\text { Economic } \\
\text { Policy } \\
\text { Developmen } \\
\text { t IndexF(x) }\end{array}$ & $\begin{array}{c}\text { Marine } \\
\text { Service } \\
\text { Industry } \\
\text { Development } \\
\text { IndexF(y) }\end{array}$ & $\begin{array}{c}\text { Marine } \\
\text { Economic Policy } \\
\text { Marine Service } \\
\text { Industry } \\
\text { Coordinated } \\
\text { Development } \\
\text { Index C }\end{array}$ \\
\hline $\begin{array}{l}\text { Antagonist } \\
\text { ic phase }\end{array}$ & 2006 & 0.29 & 0.58 & 0.44 \\
\hline \multirow{5}{*}{$\begin{array}{c}\text { Run-in } \\
\text { phase }\end{array}$} & 2007 & 0.32 & 0.65 & 0.46 \\
\cline { 2 - 5 } & 2008 & 0.36 & 0.75 & 0.49 \\
\cline { 2 - 5 } & 2009 & 0.33 & 0.76 & 0.48 \\
\cline { 2 - 5 } & 2010 & 0.34 & 0.82 & 0.49 \\
\cline { 2 - 5 } & 2012 & 0.40 & 0.86 & 0.52 \\
\cline { 2 - 5 } & 2013 & 0.34 & 0.88 & 0.49 \\
\cline { 2 - 5 } & 2014 & 0.35 & 0.95 & 0.50 \\
\cline { 2 - 5 } & 2015 & 0.40 & 0.99 & 0.51 \\
\hline
\end{tabular}


Table5. Evaluation of types of coordinated development of marine economic policy and marine service industry

\begin{tabular}{|c|c|c|c|c|}
\hline $\begin{array}{l}\text { progression } \\
\text { stage }\end{array}$ & years & $\begin{array}{c}\text { Comprehensiv } \\
\text { e Development } \\
\text { Index T }\end{array}$ & $\begin{array}{l}\text { Coupling } \\
\text { coordination } \\
\text { index D }\end{array}$ & $\begin{array}{c}\text { Type } \\
\text { evaluation } \\
\text { (all lagging in } \\
\text { the } \\
\text { development } \\
\text { of marine } \\
\text { economic } \\
\text { policy) }\end{array}$ \\
\hline $\begin{array}{l}\text { Antagonistic } \\
\text { phase }\end{array}$ & 2006 & 0.435 & 0.44 & Mild disorder \\
\hline \multirow{9}{*}{ Run-in phase } & 2007 & 0.485 & 0.47 & $\begin{array}{l}\text { Imminent } \\
\text { imbalance }\end{array}$ \\
\hline & 2008 & 0.555 & 0.52 & \multirow{7}{*}{$\begin{array}{l}\text { Barely } \\
\text { coordinated }\end{array}$} \\
\hline & 2009 & 0.545 & 0.51 & \\
\hline & 2010 & 0.580 & 0.53 & \\
\hline & 2011 & 0.630 & 0.57 & \\
\hline & 2012 & 0.605 & 0.55 & \\
\hline & 2013 & 0.620 & 0.56 & \\
\hline & 2014 & 0.650 & 0.57 & \\
\hline & 2015 & 0.695 & 0.61 & $\begin{array}{l}\text { Primary } \\
\text { coordination }\end{array}$ \\
\hline
\end{tabular}

3.2.1 The coordination and development index of marine economic policy and marine service industry are on the rise: The marine service industry development index has grown steadily, and the marine economic policy index has remained basically stable. The coupling coordination index and comprehensive development index of the marine economic policy and the marine service industry have grown steadily, and the overall degree of coordinated development has improved, going through two stages. Antagonistic stage: In 2006, the coordinated development of the marine economic policy and the marine service industry was slightly out of order, and the system was in a state of disorder at this time, the internal structure of the system was continuously adjusted, and the coordination was weak. Run-in phase: From 2007 to 2015, the development of marine economic policies remained basically stable, the development index of marine service industry increased steadily, and the comprehensive development index of the two increased greatly. The data shows that from 2006 to 2015, the development of marine economic policy lags behind that of marine economic development.

3.2.2 The marine service industry develops well, the development of marine economic policies remains stable, and it lags behind the development of the marine service industry: From 2006 to 2015, they all belonged to the lagging type of marine economic policy $(\mathrm{F}(\mathrm{y})>\mathrm{F}(\mathrm{x}))$. Over the past decade, the marine service industry has achieved stable and continuous growth, which is specifically reflected in: marine transportation, coastal tourism, and marine The coordinated and stable development of science and technology, education, marine environment and protection. In the long run, policies should focus on improving and enhancing the level of the components of the development of the marine service industry, and fundamentally ensure the sustainable development of the marine service industry.

\section{In conclusion}

The analysis results show that: during the study period, the system coupling time series evolution curve generally shows a rising trend, and the level of interaction between elements within the system is enhanced. The cumulative causal effect and the advantage of the cluster have increased, and the coordinated development level of the two has risen from the antagonistic phase to the run-in phase over time. Although the coordinated phase has not been reached during the study period, the development of the marine economic policy and the marine service industry system has stabilized. Through in-depth analysis, it can be concluded that the development of marine economic policy shows a steady curve law and the steady rise of marine service industry. Under the active, scientific and effective guidance of marine economic policy, the marine service industry has achieved a steady upward development .

In order to further promote the high-quality development of the marine service industry, the main factors of the interaction between the marine economic policy and the marine service industry system should be taken as the focus, the cohesion between the systems should be strengthened, the role and reaction mechanism should be fully exerted, and the circular cumulative causal benefit should be improved.

\section{References}

1. Wang Jiajun, "The evolution of China's marine economic policy and its impact on the development of marine economy," Liaoning Normal University Master Degree Thesis, 2019, 3-24.

2. Di Ganbin and Zhou Lin, "Evaluation of the spatiotemporal coupling and coordinated development of urbanization and marine service industry in coastal areas of my country," 2015, 88-94.

3. Lu Yayun, Yuan Feng, Li Xingyun, “The construction and application of the evaluation index system of high-quality development of my country's marine economy-based on the perspective of five development concepts," Enterprise Economics, 2019, 121-126.

4. Zheng Shangzhi, Ma Qianyu, "A Study on the Coupling Measurement of Local Government Scale and Efficiency," Cooperative Economy and Technology, 2020, 164-166.

5. Wang Ran, Cheng Jinhua, "Coupling analysis of economic society, resources and environment of the Yangtze River Delta urban agglomeration from the perspective of high quality development," Academic Forum, 2019, 1-7.

6. Zhang Guoxing, Gao Xiu, Wang Yingluo, Guo Jue, Wang Shouyang, "Measurement Coordination and Evolution of China's Energy Conservation and Emission Reduction Policies-A Study Based on Policy Data from 1978 to 2013," China PopulationResources and Environment, 2014, 62 -72.

7. Yang Li, Huang Taozhen, "Research on the Mechanism and Relationship between Ecological Civilization and New Urbanization Based on Coupling Coordination Model,'Ecoeconomics, 2019,60-65. 
8. Shu Weiying, "Research on the development of Ningbo marine service industry," Journal of Southwest Normal University, 2014, 116-120. 